\title{
Editorial
}

\section{Premio Dr. Rodolfo Céspedes Fonseca 2003.}

\author{
Dra. María Paz León-Bratti, PhD ${ }^{\prime}$
}

I Editora en Jefe Acta Médica Costarricense

ISSN 0001-6002/2004/46/1/4-5 Acta Médica Costarricense,(C2004 Colegio de Médicos y Cirujanos
Durante los últimos años, la junta de gobierno del Colegio de Médicos y Cirujanos de Costa Rica, así como los diferentes comités a el adscritos, han tratado de promover e incentivar la investigación y la publicación de trabajos científicos. Es por ello que el año pasado se instauró el premio Dr. Rodolfo Céspedes Fonseca para reconocer los mejores trabajos originales publicados en la revista $\mathrm{AMC}$, publicación científica oficial de nuestro colegio, fundada por él.

Durante el año 2003, el comité editorial recibió 48 trabajos para evaluación y en los 4 números regulares se publicaron 10 trabajos originales, 8 artículos de revisión y 6 casos clínicos entre otros. Además, en colaboración con la Asociación de Neumología y Cirugía de Tórax se publicó un suplemento especial. La Revista también participó en el proceso de recertificación, publicando 6 cuestionarios de autoevaluación.

El Dr. Céspedes inició sus estudios en la Universidad de Costa Rica en 1935 en la carrera de derecho, que en ese momento era una de las dos, junto con Farmacia, que se impartían. Cuando cursaba el segundo año, recibió el ofrecimiento de una beca para estudiar medicina en Chile la cual aceptó de inmediato. En 1945 se graduó de médico cirujano en la Universidad de Chile, regresó al país y presentó sus exámenes de incorporación al CMC en setiembre de 1946.

De 1946 a 1947 realizó su internado en el Hospital San Juan de Dios, donde obtuvo el premio al mejor médico interno en ese año. Regresó luego a Chile a realizar estudios de especialización en Anatomía Patológica en el Hospital Salvador, regresando a Costa Rica en 1950.

Entre los múltiples cargos que ocupó a partir de ese momento figuran:

- Asistente del Servicio de Anatomía Patológica del Hospital San Juan de Dios y del Hospital Central.

- Profesor de histología y patología general en la Facultad de Odontología de la UCR.

- Jefe del Servicio de Anatomía Patológica del Hospital San Juan de Dios.

- Patólogo asesor de la oficina Médico Forense del Ministerio de Salubridad

- Patólogo asesor de la lucha contra la Lepra.

- Patólogo de la lucha contra el Cáncer.

- Profesor fundador de la Escuela de Medicina de la UCR, desde donde fue maestro de muchas generaciones de médicos nacionales y de todo un grupo de especialistas en anatomía patológica en nuestro país.

- Vicepresidente y luego presidente de la Sociedad Latinoamericana de Patología. 
- El Dr. Céspedes publicó más de 59 trabajos científicos tanto en revistas nacionales como internacionales.

En 1957 el Dr. Céspedes tuvo la iniciativa de fundar la revista AMC, y como progenitor la cuidó y luchó por ella hasta llevarla a convertirse en uno de los principales medios de difusión científica-médica en nuestro país. Desde el editorial del primer número publicado en diciembre de ese año, mencionaba que 'tener un medio para la publicación de trabajos científicos y el estímulo para elevar el nivel técnico de la medicina del país, será una de nuestras principales metas'. El actual comité editorial de AMC considera que esta sigue siendo una de las más importantes metas de la revista.

Es por todos estos méritos que se eligió el nombre del Dr. Céspedes Fonseca para premiar a los mejores trabajo publicados cada año por la revista, dado que gracias al esfuerzo inicial de él, su fundador, ésta ha logrado sobrevivir por 46 años, promoviendo la publicación y el desarrollo de la investigación médica en Costa Rica.

Para otorgar el premio a los mejores trabajos originales publicados, el Comité Editorial de AMC evaluó todos los trabajos publicados en esa categoría durante el año 2003 con una serie de parámetros: estructura, contenido, referencias, beneficio al cuerpo médico nacional y repercusión en la salud pública del país. Se excluyeron de evaluación todos los artículos en los cuales figuraba como autor algún miembro del Comité Editorial de la revista.

Los trabajos escogidos como ganadores del premio Dr. Rodolfo Céspedes Fonseca año 2003 fueron los siguientes:

Tercer lugar: Hepatitis virales agudas en un hospital de adultos de 1992 a 2001, de los autores Jose Acuña Feoli, Elizabeth Umaña Solís, Mauricio Saldarriaga Londoño, Jorge Mora Duarte, Fernando Brenes Pino, Alfredo Martén Obando.

Segundo Lugar: Floraciones algales nocivas en la costa Pacífica de Costa Rica: toxicología y sus efectos en el ecosistema y la salud pública. Por los autores Enrique Freer Bustamante y Maribel Vargas Montero.

Primer Lugar: Disquinesia tardía por neurolépticos y discapacidad en usuarios de larga estancia del Hospital Dr. Roberto Chacón Paut. Del autor José Rodolfo Gutiérrez Villalobos.

Felicidades a los ganadores. 